\title{
Genetic analyses of oculocutaneous albinism types 1 and 2 with four novel mutations
}

Qi Yang, Sheng Yi, Mengting Li, Bobo Xie, Jinsi Luo, Jin Wang, Xiuliang Rong, Qinle Zhang, Zailong Qin, Limei Hang, Shihan Feng and Xin Fan ${ }^{*}$ (10

\begin{abstract}
Background: Oculocutaneous albinism (OCA) is a human autosomal-recessive hypopigmentation disorder with hypopigmentation in the skin, hair, and eyes. OCA1 and OCA2 are caused by mutations of the TYR and OCA2 genes, respectively, which are responsible for most oculocutaneous albinism. However, the incidence of oculocutaneous albinism patients in Guangxi remains unclear.

Methods: To evaluate the molecular basis of oculocutaneous albinism in thirty-six patients in Guangxi, China. Peripheral venous blood samples were collected from these unrelated patients. The TYR and OCA2 genes of all individuals were analyzed by direct DNA sequencing and the sequences compared with are reference database and bioinformatics analysis.

Results: Among the 36 OCA patients, 8(22.2\%) were found mutations on TYR gene, 28 (77.8\%) on OCA2. And we identified Twenty-seven different TYR and OCA2 mutations in these patients, including one novel TYR framshift mutation c.561_ 562insTTATTATGTGTCAAATTATCCCCCA, three novel OCA2 mutations: one nonsense mutation c.2195C > G(p.S732X), one deletation mutation(c.1139-1141 delTGG), one missense mutations c.2495A > C(p.H832P). The population screening and the bioinformatic analysis to determined the effects of the mutations, which revealed these four novel mutations were pathogenic.

Conclusions: This study expands the mutation spectrum of oculocutaneous albinism. Four novel mutational alleles c.1139-1141deITGG, c.1832 T>C and c.2195C > G and of the OCA2 gene and c.561_562insTTATTATGTGTCAAATTATCCCCCA of TYR were associated with OCA. The genotype-phenotype correlations suggest that molecular diagnosis is more accurate and important in OCA.
\end{abstract}

Keywords: Oculocutaneous albinism, TYR, OCA2, Mutation, Chinese

\section{Background}

Albinism is a group of hereditary disorders caused by a deficit in production of the pigment melanin. It can be classified as oculocutanous albinism (OCA) and ocular albinism (OA) [1]. The most common and visible type of albinism is oculocutaneous albinism, which is a group of autosomal recessive disorders with a reduction or complete absence of melanin in the skin, hair, and eyes and is often associated with ocular changes including photophobia, decreased visual acuity and nystagmus [2]. OCA is subdivided into 7 subtypes (OCA 1-7) based on

\footnotetext{
* Correspondence: yangqisklmg126@126.com

Department of Genetic and Metabolic Central Laboratory, Guangxi Maternal and Child Health Hospital, No.59, Xiangzhu Road, Nanning, China
}

genes as follows: TYR (OCA1), OCA2 (OCA2), TYRP1 (OCA3), SLC45A2(OCA4), SLC24A5 (OCA6), LRMDA (OCA7) and OCA5 located on chromosome 4q24 and the subtypes can only be accurately diagnosed by genetic gene [3]. OCA affects one in 17,000 individuals worldwide [4]. The prevalence of OCA subtypes differs among ethnic groups. OCA1 has been reported to be the most subtype in Caucasians and accounts for approximately 50\% of cases worldwide $[5,6]$. OCA2 is the most common form of albinism worldwide; in which the prevalence is estimated as 1/30000 due to Caucasians [5], and in the African-American population, in which the prevalence is estimated to be 1:10,000 [6]. OCA3,or rufous OCA (ROCA), it has been reported to affect 1:8500 individuals

(c) The Author(s). 2019 Open Access This article is distributed under the terms of the Creative Commons Attribution 4.0 International License (http://creativecommons.org/licenses/by/4.0/), which permits unrestricted use, distribution, and reproduction in any medium, provided you give appropriate credit to the original author(s) and the source, provide a link to the Creative Commons license, and indicate if changes were made. The Creative Commons Public Domain Dedication waiver (http://creativecommons.org/publicdomain/zero/1.0/) applies to the data made available in this article, unless otherwise stated. 
in Africa, but is virtually unseen in Caucasians and Asiatic populations. OCA3,or rufous OCA (ROCA), it has been reported to affect 1:8500 individuals in Africa, but is virtually unseen in Caucasians and Asiatic populations [7]. OCA4 were reported to explain the disease in approximately $18 \%$ of Japanese patients, whereas it is very rare in in Korean, Chinese,Caucasians populations [7, 8]. In Han Chinese, the prevalence of OCA is about 1:18000, and OCA1 is the most subtype [9].

OCA1, is caused by mutations of TYR on chromosome $11 \mathrm{q} 14$ and it exhibits the most severe phenotype [10]. More than 300 mutations in TYR have been identified in individuals with OCA1 (MIM 203100) phenotype [11]. There are two subtypes of OCA1: OCA1A and OCA1B. OCA1A is caused by a mutation causing a complete lack of tyrosinase activity, which presents with milky skin and white hair throughout life. Whereas type 1B (OCA1B) is caused by the mutations causing reduced activity of tyrosinase, and the white/light yellow hair and white skin of individuals with OCA1B can darken overtime [4, 12]. Oculocutaneous albinism type II (OCA2-MIM 203200), an autosomal recessive disorder in which the biosynthesis of melanin pigment is reduced in skin, hair, and eyes, which has been described in all major ethnic groups [13]. OCA2 is caused by mutations of OCA2 (previouslycalled $\mathrm{P}$ gene), which is located on chromosome 15q11.2-q12 and consists of 24 exons (23 coding). More than $140 \mathrm{mu}$ tations have been identified in its gene body (HGMD Professional http://www.hgmd.cf.ac.uk/ac/all.php). Although the function of $O C A 2$ is not precisely characterized, the $\mathrm{p}$ protein consists of 12 transmembranes panning regions and is an integral component of themelanosomal membrane [13]. But it could be involved in the transport of tyrosine, the precursor to melanin synthesis, within the melanocyte. Regulates the $\mathrm{pH}$ of melanosome and the melanosome maturation [14-16].

As mutations in the TYR and OCA2 genes account for the majority of OCA cases, we have analyzed and examined the TYR and OCA2 genes in thirty-six patients with oculocutaneous albinism in Guangxi Zhuang Autonomous Region of China in the present study to identify the causative mutations for each of them.

\section{Methods}

\section{Patients}

August 2017 to May 2019, thirty-six unrelated OCA patients (33 minors and 3 adults) and their parents and 300 unaffected subjects were recruited in our study. All the patients were from the provinces of Guangxi, China. The families were referred to the Guangxi Maternal and Child Health Hospital for advice about diagnosis or highly suspected in patients with non-syndromic ocular albinism and Genetic testing demands of the patient. We followed the criteria for the differentiation of OCA1A, OCA1B and
OCA2 as described [16]. Among the 36 OCA patients, sixteen were clinically diagnosed as OCA1A or OCA1B, twenty were diagnosed as OCA2 (Table 1). In all the 36 OCA patients, varying colors of the skin and hair, and abnormal ophthalmological findings including photophobia, nystagmus and reduced visual acuity were observed. The 300 normal controls matched by gender and ethnic origin were selected and recruited from healthy individuals from the Center of Genetic Metabolism Genetic Metabolism at Guangxi Maternaland Child Health Hospital. All participants agreed to carry out a genetic analysis and singed written informed consent for the study approved by the Genetic and Metabolic Central Laboratory of Guangxi Zhuang Autonomous Region Women and Children Care Hospital (Nanning, China).

\section{Mutation screening}

Peripheral blood samples were collected from thirty-six unrelated patients and 300 unaffected subjects, and genomic DNA was extracted from peripheral blood of the trios using Lab-Aid DNA kit (Zeesan Biotech Co, Ltd., China), DNA concentration was determined with NanoDrop ND2000 spectrophotometer and soft-ware (NanoDrop Technologies, Berlin, Germany). Polymerase chain reaction (PCR) primers were designed using Primer3 (http:// bioinfo.ut.ee/primer3-0.4.0/) to cover five coding exons of the TYR gene and 2-24 exons of the OCA2 gene (Tables 2 and 3). Appropriate annealing temperatures were selected for PCR. PCR products were analyzed with agarose gel electrophoresis and used for Sanger sequencing. When a potential novel mutation was considered after careful check with the ClinVar (http://www.ncbi.nlm.nih.gov/), HGMD (http://www.hgmd.cf.ac.uk/ac/), HPSD (http:// liweilab.genetics.ac.cn/HPSD/), Albinism Datebase, (http:// www.ifpcs.org/albinism/oca2mut.html) and the SNP (http://www.ncbi.nlm.nih.gov/SNP/) databases, direct sequencing of the amplified PCR products from the same region of the 300 unaffected subjects was applied to exclude the possibility of polymorphism.

\section{In silico analysis}

Four softwares were used to analyze the functional effects of novel variants, including SIFT (http://sift.jcvi.org/), PolyPhen2 (http://genetics.bwh.harvard.edu/pph2/), Mutation Taster (www.mutationtaster.org). Multiple amino acid sequence align?ment from different species was generated by HomoloGene (https://www.ncbi.nlm.nih.gov/ homologene). Classification of variants according to the ACMG standards and guidelines [17].

\section{Results}

Mutation identification and analysis

Sanger sequencing analysis of the relevant PCR fragments in exons of the TYR and OCA2 genes revealed 


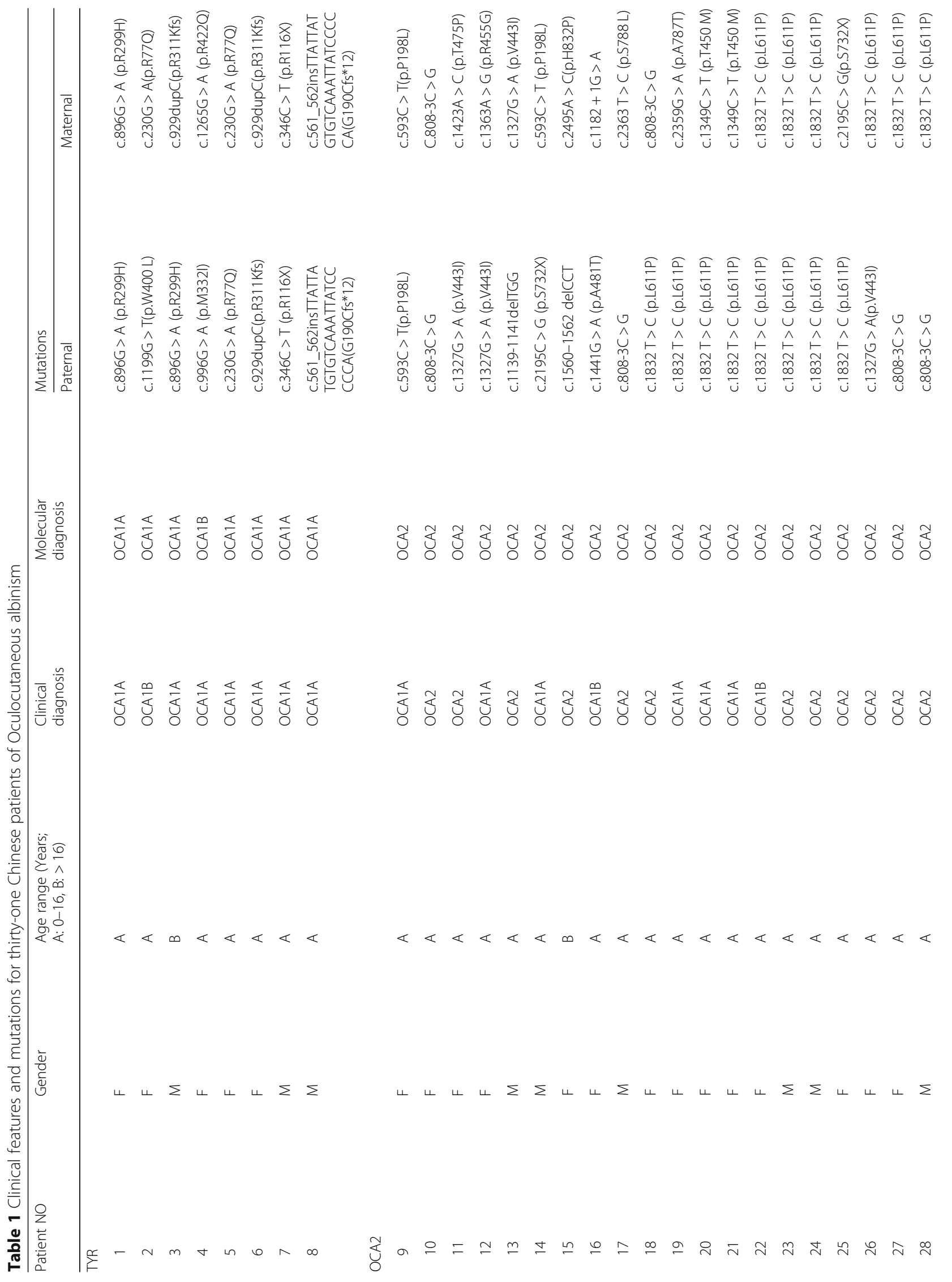




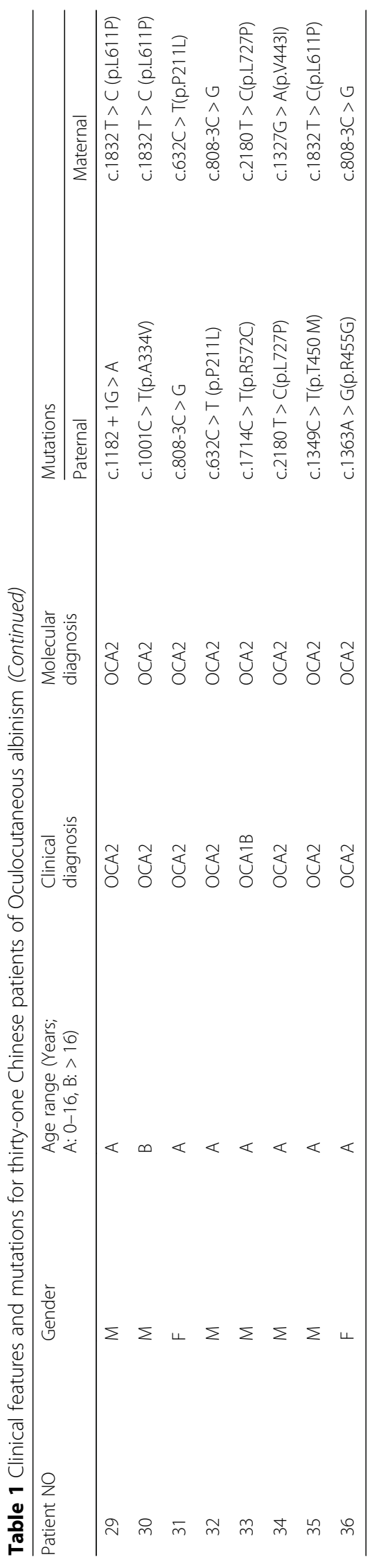


Table 2 PCR primers and conditions used for mutation analysis of the tyrosinase gene

\begin{tabular}{lllll}
\hline Exon & Sequence $\left(5^{\prime}-3^{\prime}\right)$ & & \\
\hline 1 & Forword & Reverse & Product size $($ bp $)$ & Annealing temperature $\left({ }^{\circ} \mathrm{C}\right)$ \\
2 & TGCTGGAGGTGGGAGTGGTAT & AAATACAAGATACATTGAGAGT & 864 & 56 \\
3 & ATTTCTGCCTTCTCCTAC & TAGGACTTTGGATAAGAGACTGTAA & 354 & 56 \\
4 & CCAGAATGTAAAGAGTCTCAATACGGAA & TCACAGACAATAGACTACCATAACT & 421 & 56 \\
5 & TATGTACCACTTAACTGTG & ACTGCTCTTCACATGGTGC & 2269 & 62 \\
\hline
\end{tabular}

twenty-five different variants in thirty-one unrelated individuals. The variants included ninteen known mutations: nine TYR mutations and thirteen OCA2 mutations (Table 1); one novel TYR framshift mutation c.561_562 insTTATTATGTGTCAAATTATCCCCCA(G190Cfs*12), three novel OCA2 mutations including one nonsense mutation c. $2195 \mathrm{C}>\mathrm{G}(\mathrm{p} . \mathrm{S} 732 \mathrm{X})$, one deletation mutations (c.1139-1141delTGG), one missense mutations c.2 495A > C(p.H832P), all novel variants were not detected in our 300 control individuals (Fig. 1). Among these 36 OCA patients, 26 patients were identified of compound heterozygous mutations, and other 10 patients were were identified of homozygous mutations (Additional file 1) gene, changes also seen in the father and mother.) . The frequency percentage of the detected OCA2 mutations are shown in Table 4. Of these, the c.1832 T > C(p.L611P) mutation was most frequent (32.1\%), followed by the c.808-3C > G mutation (16.10\%), c.1327 G > A(p.V443I) (8.90\%), c.1349C > T(p.T450 M) (5.40\%) and c.593C $>\mathrm{T}$ (p.P198L) (5.40\%); the other mutations were observed only once or twice.

\section{In silico analysis novel variants}

Our studies revealed four novel variants, which located in TYR and OCA2, respectively (Table 1 and Fig. 1). The functional sites of the SIFT, PolyPhen2.0 and Mutation

Table 3 PCR primers and conditions used for mutation analysis of the OCA2 gene

\begin{tabular}{|c|c|c|c|c|}
\hline Exon & Sequence $\left(5^{\prime}-3^{\prime}\right)$ & & & \\
\hline & Forword & Reverse & Product size(bp) & Annealing temperature $\left({ }^{\circ} \mathrm{C}\right)$ \\
\hline 2 & ATGCTGGAACTCTGGGACC & GGAACGATGCTCATGGAAAC & 438 & 60 \\
\hline 3 & GGTCTITCTTATGGTGTCTTC & TCTCAAGTTCTCCAGCATAC & 359 & 60 \\
\hline 4 & CAGGGTTGATTCGGTGCCAT & CTTCTTCACGCTGCTGGTITG & 390 & 60 \\
\hline 5 & AAGTGTCTGAGTCTGGGCAAC & GGCTGAACAGGGAAGTGGTAAG & 442 & 60 \\
\hline 6 & CAGTAGCCCCATCATCACATC & CCTTCAGCAGCAGTCACAAC & 269 & 60 \\
\hline 7 & AACGCATTTCTTCACACACTG & CCCATCAAATCCATTCAAGAG & 354 & 60 \\
\hline 8 & GTTGGGATTACAGGCGTGAG & TGCTGACCTGGTGCTGTGTG & 537 & 60 \\
\hline 9 & GCCTGTGCTCACTGCTCTTC & TTCCTGTATGGTTCCCTTTCT & 476 & 60 \\
\hline 10 & TGTATGTGTCTGTGGGGTGTC & CGAAAGCCTGAATCCTGGAAC & 323 & 60 \\
\hline 11 & GGCAAGTGGATGGTGAGATTTC & CCATAGCCCCATTCCATTC & 375 & 60 \\
\hline 12 & ATGTGGTGGCTITCAGAG & TGAGTACCCTITTCCTTGAC & 405 & 60 \\
\hline 13 & TGTTAGTITGGCTCCCTGTTC & ССTATGTCTTCCACCTCCTG & 469 & 60 \\
\hline 14 & AGGGTTTGGTGGCTGGAGG & GTGGAGGTGTGCGTITACTGG & 421 & 62 \\
\hline 15 & CACGCCATTCTCCTGCCTC & CATCCAGCAACCCATCAAC & 468 & 60 \\
\hline 16 & ATGTCGGCTTTGTCGTCTG & CTCGGCTGTGTACCCCCTG & 520 & 60 \\
\hline 17 & CCAGCCAACAAATGAAGCC & TCCCCATCCACTCACACAC & 379 & 60 \\
\hline 18 & TGTCGTGATTCCAGTTGCGT & СCСTCCATCTCAGCCCTCTC & 332 & 60 \\
\hline 19 & TCTTGATTACAGTGTTGGTT & CTTCATTGTITCCACTTAG & 442 & 60 \\
\hline 20 & CTGCTGTTGGACTITTC & ATTACTGAGGCTGGTGT & 538 & 60 \\
\hline 21 & TCGTGATGGGTAAGAGGAAGG & AAGCAAGCAAGCAAGCACAG & 528 & 60 \\
\hline 22 & TCAGGACCAGGAGGACCAGTTG & CAGAGAATGGGAAGGAACGGAG & 507 & 60 \\
\hline 23 & TGCGTGTGTGTGTGTITCC & AATCTCCCCTACACCACAGTC & 389 & 60 \\
\hline 24 & ATAGATGAACAAACAGAGGCT & GAAAGGACACACAGAGGAGG & 566 & 60 \\
\hline
\end{tabular}




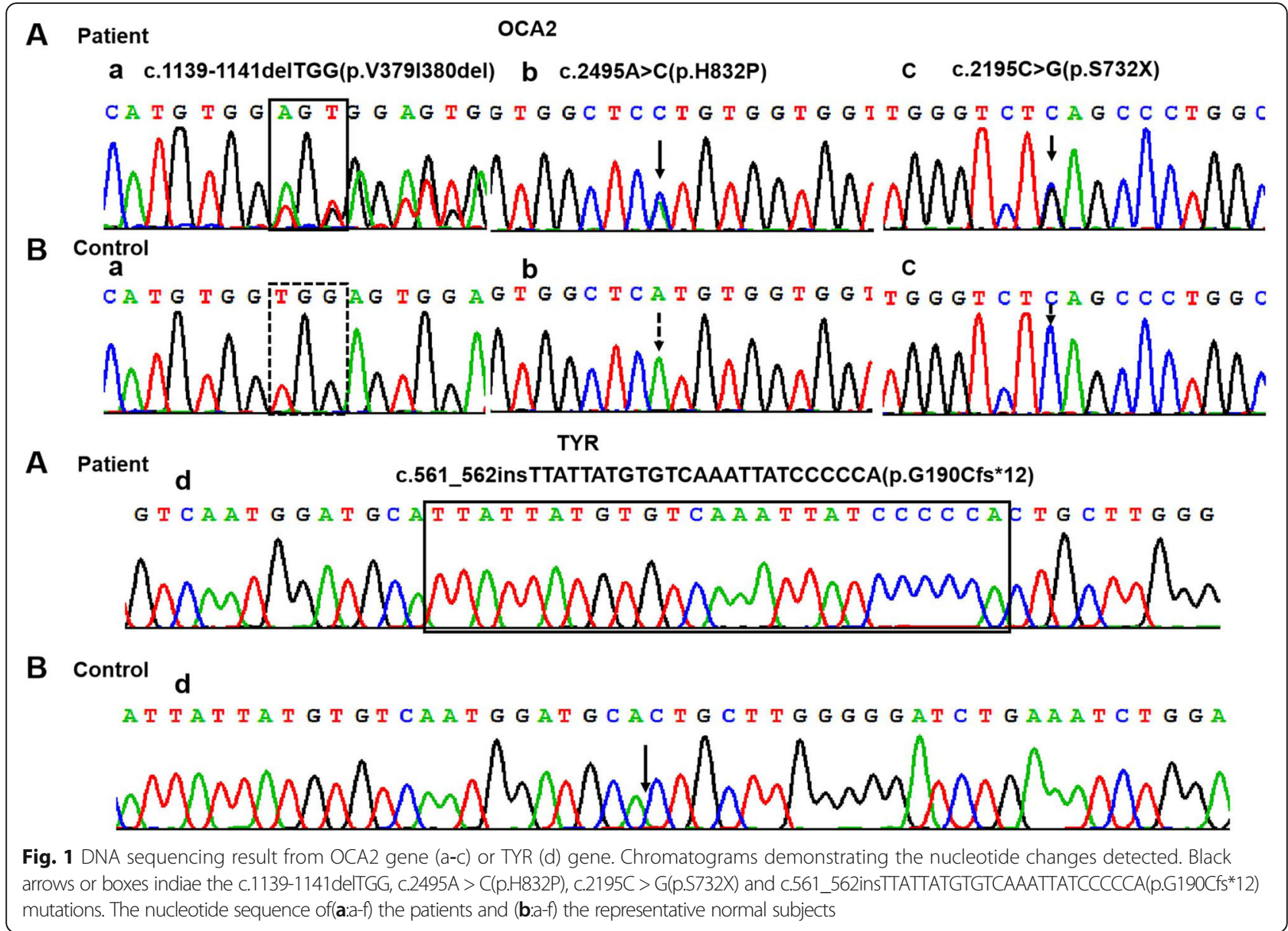

Tasters predicted that the novel missense variant of c.2495A > C(p.H832P) likely had deleterious effects, by damaging the function of the OCA2 protein. MutationTaster prediction showed that results displayed that the frameshift mutation of c.561_562insTTATTATGTGTCAA ATTATCCCCCA(G190Cfs*12) in TYR, the nonsense mutation of c.2195C > G(p.S732X) and the deletation mutation c.1139-1141delTGG(p.V379I380del) in OCA2 were deleterious. Multiple amino acid sequence alignment of TYR and OCA2 amino acid sequences showed that the novel mutations took place at highly conserved regions (Table 5). According to the ACMG standards and guidelines for the interpretation of sequence variants, these novel mutations is likely pathogenic or pathogenic (Table 5).

\section{Discussion}

Oculocutaneous albinism is a recessive hereditary group of diseasesis characterized by reduce or completely absent melanin synthesis despite adequate numbers of structurally normal melanocytes in the skin, hair, and eyes [16]. The common disease-causing genes of OCA are TYR and $O C A 2$ gene. Tyrosinase is a coppercontaining glycoprotein and a oxidase and involved in the formation of pigments, such as melanins and other polyphenolic compounds [11]. The mutations of TYR causing the OCA1 are delineated by five key functional sites of the enzyme; two locations copper-binding sites while others are located at the 3 '-end of the copper B-binding region near the amino terminus of the protein, and between the $\mathrm{CuA}$ and CuB domains [18].

OCA 2 is caused by mutations in the OCA 2 gene, resulting in alterationsin the p protein, and which might in turn affect melanin biosynthesis. OCA2 is a transmembrane protein found in the melanosomal membrane. Numerousstudies suggest that this protein could be involved in the transport of tyrosine, the precursor to melanin synthesis within the melanocyte and regulates the $\mathrm{pH}$ of melanosome and the melanosome maturation [19-21].

In this study, we identified compound heterozygous and homozygous mutations in TYR or OCA2 in 36 Guangxi Chinese individuals by direct sequencing. The distribution of mutational OCA genes was slightly shifted, OCA2 is the most common type in our oculocutaneous albinism population in Guangxi, China. In a total of 36 OCA patients, 8 were clinically diagnosed with OCA1, 28 were diagnosed with OCA2 (Table 1). Of 
Table 4 Allelic frequencies of the OCA2 gene in 26 Chinese OCA2 patients

\begin{tabular}{|c|c|c|c|}
\hline Nucleotide change & Amino acid change & Status (Number of the patients) & Frequency percentage(\%) \\
\hline C. $808-3 C>G$ & splice site & Homo (1), Hetero (6) & 15.4 \\
\hline c. $1327 G>A$ & p.V443| & Hetero (5) & 9.6 \\
\hline C. $1423 \mathrm{~A}>\mathrm{C}$ & p.T475P & Hetero (1) & 1.9 \\
\hline c.1363A > G (p.R455G) & p.R455G & Hetero (1) & 1.9 \\
\hline c.1139-1141delTGG & Other site & Hetero (1) & 1.9 \\
\hline c. $2195 C>G$ & p.S732* & Hetero (2) & 3.8 \\
\hline c.593C > T & p.P198L & Homo (1), Hetero (1) & 5.8 \\
\hline C.1560-1562 delCCT & Other site & Hetero (1) & 1.9 \\
\hline C. $2363 \mathrm{~T}>\mathrm{C}$ & p.H832P & Hetero (1) & 1.9 \\
\hline c.1441G > A (p.A481T) & p.A481T & Hetero (1) & 1.9 \\
\hline$c .1182+1 G>A$ & splice site & Hetero (2) & 3.8 \\
\hline C.2363 T > C & p.S788 L & Hetero (1) & 1.9 \\
\hline C. $1832 \mathrm{~T}>\mathrm{C}$ & p.L611P & Homo (3), Hetero (10) & 30.8 \\
\hline c.2359G > A (p.A787T) & p.A787T & Hetero (1) & 3.8 \\
\hline c. $1349 \mathrm{C}>\mathrm{T}$ & p.T450 M & Hetero (2) & 3.8 \\
\hline c. $632 C>T$ & p.P211L & Hetero (2) & 3.8 \\
\hline C. $1714 \mathrm{C}>\mathrm{T}$ & p.R572C & Hetero (1) & 1.9 \\
\hline c.2180 T > C) & p.L727P & Hetero (2) & 3.8 \\
\hline c.1001C > T (p.A334V) & A334V & Hetero (1) & 1.9 \\
\hline
\end{tabular}

the 36 molecularly diagnosed patients, 268 carried two mutational alleles and 5 carried one mutational allele. Of the identified patients, we found apparent pathological TYR mutations in $22.2 \%$ of the patients ( 8 of 36 ), OCA2 mutations in $77.8 \%$ (28 of 36 ) (Table 4 ).

Among patients with OCA1, most of patients genotypically have "tyrosinase-negative" OCA1A and patient 4 have OCA1B, associated with low residual tyrosinase catalytic activity. The mutation c.896G > A(p.R299H) has already been reported [22] which is located in the central portion of tyrosinase and causing the enzyme activity deficient, therefore, the patient was classified as OCA1A. Tomita Yoshioka et al. [23] demonstrated that the frameshift mutation c.929dupC(p.R311Kfs) resulting in a truncated inactive tyrosinase. The heterozygous mutations c.230G > A(p.R77Q) and c.1199G > T(p.W400 L) in the TYR gene identified in patient 2 were firstly reported in Japanese and Taiwan patients [24]. The mutation of c.230G $>A(p . R 77 Q)$ is the major ones in Japanese patients with OCA1A [25]; Chang-Hai Tsai et al. [26] demonstrated that the mutation of c.1199G > $\mathrm{T}(\mathrm{p} . \mathrm{W} 400 \mathrm{~L})$ might disrupt the second copper binding site of this polypeptide. Therefore, the patients $(1-3,5-8)$ were classified as OCA1A. Patient 4 was compound heterozygous for c.996G > A (p.M332I) and c.1265G > A (p.R422Q) changes in the TYR gene. Grønskov K et al. identified the M332I allele in Denmark for the first time [27], and in 1991, Giebel LB et al. demonstrated the substitution of $\mathrm{R} 422 \mathrm{Q}$ results in a tyrosinase polypeptide that is temperature-sensitive [11], the patient was classified as OCA1B. According to the study of Richards $\mathrm{S}$ et al., c.346C > T (p.R116X) was a pathegentic mutation, which resulted in premature termination codon downstream [17]. To the best of our knowledge, c.561_562insTTATTATGT GTCAAATTATCCCCCA(G190Cfs*12) was a novel mutation, which was not present in the HGMD Professional Database, dbSNP, or the 1000 Genomes database. The variant caused a frameshift alteration after codon 190 leading to a premature termination codon (PTC) which located at codon 202 and resulting in a inactive tyrosinase .

There, we analyzed the genetic defects underlying OCA2 in 28 albino patients (patients 9-36, Table 1), and identified sixteen known known mutations, three novel mutations. Except the novel mutations, other 16 mutations have been reported [16, 27-35], (https://www.scholarmate.com/S/ ivheaf]. Pei-Wen Chiang et al. [24] identified the c.808$3 \mathrm{C}>\mathrm{G}$ allele in Hispanic for the first time, in their studies, c.808-3C > G would affect the splicing of OCA2 and induce abnormal mRNA splicing. In our study, Seven Patients were inherited this missense substitutions and one patient was homozygous for c.808-3C $>\mathrm{G}$, this is the first time report in Chinese. The c.808-3C $>\mathrm{G}$ splicing site mutation represents a significant proportion of the $P$ gene mutations (16.1\%) in our oculocutaneous albinism population in Guangxi, China. The site of c.1832 T > C has been reported by Chunyue Miao as a pathogenic mutation 


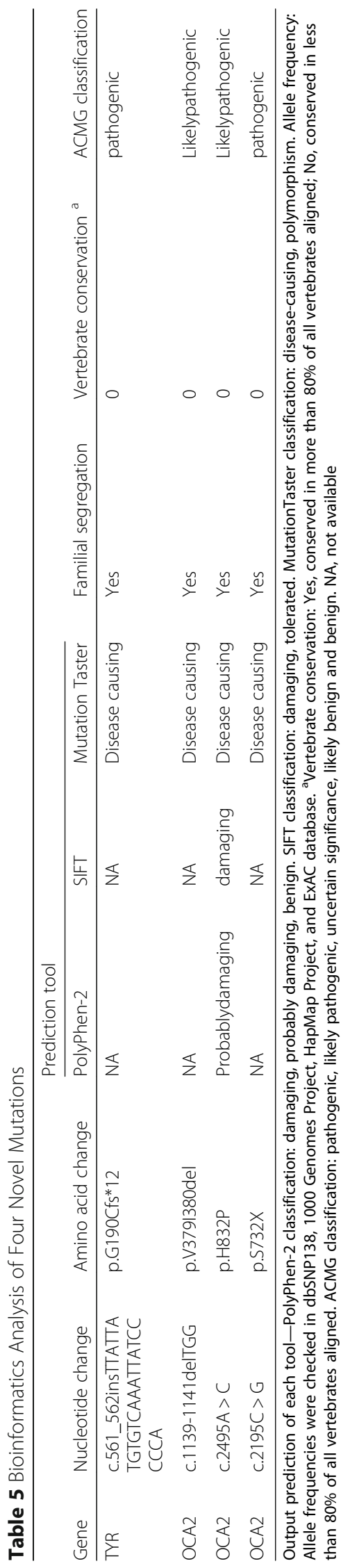


[https://www.scholarmate.com/S/ivheaf]. In our studies, there are 14 paitents $(18-30,35)$ who carries the variant c. $1832 \mathrm{~T}>\mathrm{C}$ in the OCA2 gene, and the phenotype of the patients were classified as OCA1A or OCA1B. The variant of c.1832 T > C(p.L611P) was occur at the in tracellular regions and it would contribute to the tyrosinase activity in a double heterozygous with other mutational or homozygous state allele in the Chines people. High frequency (30.8\%) of mutation c.1832 $\mathrm{T}>\mathrm{C}$ in our patients, which suggest that L611P may be a common P gene mutation associated with the typical OCA2 phenotype in oculocutaneous albinism population in Guangxi, China. As a common tyrosinase mutation of c.1327G > A(p.V443I) [5, 36], which also have a higher proportion in our albino population. The splice site mutation $(\mathrm{c} .1182+1 \mathrm{G}>\mathrm{A})$ is expected to eliminate splicing following exon 11, and causes exons 11-12 skipping, lead to aberrant splicing of the transcript. Aihua Wei et al. [16] identified the c.1182 +1G > A allele in a China patient for the first time, in their study, they didn't find the other mutation allele of the patient. In our study, patient 16 and 29 were compound heterozygous for c. $1182+1 \mathrm{G}>$ A and c.1441G > A (p.A481T) or c.1832 T > C (p.L611P) changes in the OCA2 gene. Aihua Wei et al. [16] also identified the c.1560-1562delCCT allele in a Chinese patient for the first time, and the Clinical diagnosis was OCA1B, the variant causing the structure of transmembrane domains. As the study has reported that most missense mutations occur in the loops between the transmembrane domains [37], the mutations of P211L, A334V, V443I, T475P, R455G, P198L, T450 M, A481T, R572C, S788 L, and A7 $87 \mathrm{~T}$ were close to the interface between the transmembrane domains and the intra- or extracellular regions.

Of the 19 distinct mutations in the OCA2 gene, three novel mutations have not been presented in dbSNP (http://www.ncbi.nlm.nih.gov/dbvar), the 1000 Genomes Database (http://browser.1000genomes.org/index.html), the HGMD Professional Database (http://www.hgmd.cf. ac.uk/ac/all.php), or the Albinism Datebase (http://www. ifpcs.org/albinism/oca2mut.html). To the best of our knowledge, c.1139-1141delTGG in the OCA2 gene was a novel mutation, the mutation occur within dinucleotide repeats and may have arisen because of slipped mispairing, and it located at extracellular regions. The mutation of c.2195C > G(p.S732X) change from TAC to TAG which is a novel mutation and located in the structure of transmembrane domains resulted in premature termination codon downstream. The truncated protein lacked transmembrane domains, which might have caused the transport of tyrosine dysfunction and the precursor to melanin synthesis dysfunction and resulted in location of the protein in the nucleus. The c.2495A > C(p.H832P) mutation which located in the structure of transmembrane domains and the hydrophilic histidine becomes hydrophobic proline which may change the transmembrane structure of OCA2, and further affect the tyrosinase activity.

In our study, the clinical phenotypes of 26 OCA2 patients identified showed a wide variety OCA. The Sviderskaya studies [34] shows that the A481T allele had approximately $70 \%$ functional activity in melanogenesis compared with that of the wild-type human P cDNA, furthermore, p.481Thr was reported to be an Asian-specific hypopigmentation allele [38]. Jeppe D. Andersen's date [35] showed that p.481Thr and p.443Ile was sufficient to lower the pigmentation levels in healthy individuals. These findings suggesting that the novel alleles of c.1139-1141delTGG, c.2195C > $\mathrm{G}(\mathrm{p} . \mathrm{S} 732 \mathrm{X})$ and c.2495A $>\mathrm{C}(\mathrm{p} . \mathrm{H} 832 \mathrm{P})$,might have no or very low functional activity in melanogenesis. The missense, splicing and deletion mutations destroyed the spatial structure and the integrity of the OCA2 protein, which would delayed the activity of the OCA2 protein different degrees in melanogenesis. Functional studies of the variants is particularly important on the relationships of phenotypes and genotypes of the $\mathrm{P}$ gene, and the mechanism for this need futhuer study.

\section{Conclusion}

In summary, we reported thirty six OCA patients and the molecular basis of their disease were identified by PCRsequencing of all exons of the TYR and OCA2 genes. This study expands the mutational database in humans. It is the first report of the c.1714C $>\mathrm{T}(\mathrm{p} . \mathrm{R} 572 \mathrm{C}), \mathrm{c} .1139-1141 \mathrm{~d}$ elTGG and c.2195C > G(p.S732X) mutations in the P gene and c.561_562insTTATTATGTGTCAAATTATCC CCCA(G190Cfs*12) in TYR gene. The study shows that OCA2 may be the most common type and the alleles of c. $1832 \mathrm{~T}>\mathrm{C}(\mathrm{p} . \mathrm{L} 611 \mathrm{P})$, c.808-3C $>\mathrm{G}$ may be the hotspots of OCA2 in oculocutaneous albinism population in Guangxi, China. Molecular genetic testing of TYR, $O C A 2$ is a useful tool for clinical diagnosis and genetic counseling of OCA.

\section{Additional file}

Additional file 1: Figure S1. DNA sequencing result from TYR (Patient1-8) and OCA2 (Patient9-36) gene, changes also seen in the father and mother. (DOCX $999 \mathrm{~kb})$

\section{Abbreviations \\ OCA: Oculocutaneous albinism; OCA2: Oculocutaneous albinism II gene; SLC45A2: Solute carrier family 45, member 2 gene; TYR: Tyrosinase gene; TYRP1: Tyrosinase related protein 1 gene}

Acknowledgements

We are grateful to the families for participating in this study.

\section{Authors' contributions}

QY designed the study and drafted the manuscript; XF, SY, MTL and BBX participated in the study design; JSL and XF collected the clinical data;QY, SY, MTL, BBX, JW, XLR, ZLQ, QLZ and LMH participated in collecting samples and experiments; SHF, JSL and JW extracted, analyzed, and interpreted the 
data;XF and YQ participated in the study coordination and revised the manuscript. All authors read and approved the final version of the manuscript.

\section{Funding}

This work was supported by the Project of Yu-Miao (Grant No. GXWCHYMJH-2017006), which has been used for the patient recruitment and determining genetic variants. This study was also supported by the Open Project Program of the Shanghai Key Laboratory of Birth Defect (grant no. 16DZKF1014), which has been used for validation of the pathogenicity of identified variants. The funders are not involved in the study design, data collection and analysis, performing experiments and in writing the manuscript.

\section{Availability of data and materials}

All data generated or analysed during this study are included in this published article and its supplementary information files.

\section{Ethics approval and consent to participate}

All procedures in this study were approved by the Institutional Review Boards and Ethics Committees of Guangxi Maternal and Child Health Hospital. Detailed written informed consent was obtained from all participants. For the patients who are underage, written informed consent for participation in this study was obtained from the patients' parents or guardians.

\section{Consent for publication}

Not applicable.

\section{Competing interests}

The authors declare that they have no competing interests.

Received: 14 January 2019 Accepted: 4 June 2019

Published online: 13 June 2019

\section{References}

1. Justin R. Federico; Karthik Krishnamurthy. Albinism. StatPearls [Internet]. Treasure Island (FL): StatPearls Publishing. 2019-2018.

2. King RA, Olds DP. Hairbulb tyrosinase activity in oculocutaneous albinism: suggestions for pathwaycontrol and block location. Am J Med Genet. 1985; 20:49-55.

3. Arveiler B, Lasseaux E, Morice-Picard F. Clinical and genetic aspects of albinism. Presse Med. 2017;46:648-54. https://doi.org/10.1016/j.lpm.2017.05.020.

4. Gronskov K, Ek J. Oculocutaneous albinism. Orphanet Journal of Rare Diseasea. 2007:2:43.

5. Hutton SM, Spritz RA. Comprehensive analysis of oculocutaneous albinism among non-Hispanic caucasians shows that OCA1 is the most prevalent OCA type. J Investig Dermatol. 2008;128:2442-50. https://doi.org/10.1038/jid. 2008.109.

6. Rooryck C, Morice-Picard F, Elcioglu NH, Lacombe D, Taieb A, Arveiler B. Molecular diagnosis of oculocutaneous albinism: new mutations in the OCA1-4 genes and practical aspects. Pigment Cell Melanoma Res. 2008;21: 583-7. https://doi.org/10.1111/j.1755-148X.2008.00496.X.

7. Rooryck C, Morice-Picard F, Elçioglu NH, Lacombe D, Taieb A, Arveiler B. Molecular diagnosis of oculocutaneous albinism: new mutations in the OCA1-4 genes and practical aspects. Pigment Cell \& Melanoma Research. 2008;21:583-7.

8. Inagaki K, Suzuki T, Shimizu H, et al. Oculocutaneous albinism type 4 is one of the most common types of albinism in Japan. Am J Hum Genet. 2004;74: 466-71.

9. Wei A, Yang X, Lian S, Li W. Implementation of an optimized strategy for genetic testing of the Chinese patients with oculocutaneous albinism. J Dermatol Sci. 2011;62:124-7. https://doi.org/10.1016/j.jdermsci.

10. Giebel LB, Strunk KM, Spritz RA. Organization and nucleotide sequences of the human tyrosinase gene and a truncated tyrosinase-related segment. Genomics. 1991;9:435-45.

11. Shah SA, Din SU, Raheem N, Daud S, Mubeen J, Nadeem A, et al. Identification of a novel mutation (p.lle198Thr) in gene TYR in a Pakistani family with nonsyndromic oculocutaneous albinism. Clin Exp Dermatol. 2014;39:646-8. https://doi.org/10.1111/ced.12382.

12. Simeonov DR, Wang $X$, Wang $C$, Sergeev $Y$, Dolinska $M$, Bower $M$, et al. Adams DR. DNA variations in oculocutaneousalbinism: an updated mutation list and current outstanding issues in molecular diagnostics. HumMutat. 2013;34:827-35. https://doi.org/10.1002/humu.22315.

13. Kamaraj B, Purohit R. Computational screening of disease-associated Mutationsin OCA2 gene. Cell Biochem Biophys. 2014;68:97-109. https://doi. org/10.1007/s12013-013-9697-2.

14. Lee ST, Nicholls RD, Jong MT, Fukai K, Spritz RA. Organization and sequence of the human $\mathrm{P}$ gene and identification of a new family of transport proteins. Genomics. 1995;26:354-63.

15. Brilliant $\mathrm{MH}$. The mouse $\mathrm{p}$ (pink-eyed dilution) and human $\mathrm{P}$ genes, oculocutaneous albinism type 2 (OCA2), and melanosomal pH. Pigment Cell Res. 2001;14:86-93.

16. Montoliu L, Montoliu L, Grønskov K, Wei AH, Martínez-García M, Fernández A, Morice-Picard F, et al. Increasing the complexity: new genes and new types of albinism. Pigment Cell Melanoma Res. 2014;27:11-8. https://doi. org/10.1111/pcmr.12167.

17. Richards S, Aziz N, Bale S, Bick D, Das S, Gastier-Foster J, et al. Standards and guidelines for the interpretation of sequence variants: a joint consensus recommendation of the American College of Medical Genetics and Genomics and the Association for Molecular Pathology. Genetics in medicine : official journal of the American College of Medical Genetics. 2015:17:405-24.

18. Toyofuku K, Wada I, Valencia JC, Kushimoto T, Ferrans VJ, Hearing VJ. Oculocutaneousalbinism types 1 and 3 are ER retention disease: mutation oftyrosinase Tyrp1 can affect the processing of both mutantand wild-type proteins. FASEB J. 2001;15:2149-61.

19. Chen K, Manga P, Orlow SJ. Pink-eyed dilution protein controls the processing of tyrosinase. Mol Genet Genomic Med. 2016:4:420-30.

20. Toyofuku K, Valencia JC, Kushimoto T, Costin GE, Virador VM, Vieira WD, et al. The etiology of oculocutaneous albinism (OCA) type II: the pink protein modulates the processing and transport of tyrosinase. Pigment Cell Res. 2002;15:217-24

21. Rosemblat S, Durham-Pierre D, Gardner JM, Nakatsu Y, Brilliant MH, Orlow SJ. Identification of a melanosomal membrane protein encoded by the pink-eyed dilution (type II oculocutaneous albinism) gene. Proc Natl Acad Sci U S A. 1994;91:12071-5

22. Tripathi RK, Durham-Pierre D, Gardner JM, Nakatsu Y, Brilliant MH, Orlow SJ. Tyrosinase gene mutations in type I (tyrosinase-deficient) oculocutaneous albinism define two clusters of missense substitutions. Am J Med Genet. 1992:43:865-71.

23. Tomita Y, Takeda A, Okinaga S, Tagami H, Shibahara S. Human oculocutaneous albinism caused by single base insertion in the tyrosinase gene. Biochem Biophys Res Commun. 1989;164:990-6.

24. Tripathi RK, Strunk KM, Giebel LB, Weleber RG, Spritz RA. Tyrosinase gene mutations in type I (tyrosinase-deficient) oculocutaneous albinism define twoclusters of missense substitutions. Am J Med Genet. 1992;43:865-71.

25. Tomita Y, Miyamura Y, Kono M, Nakamura R, Matsunaga J. Molecular bases of congenital hypopigmentary disorders in humans and oculocutaneous albinism in Japan. Pigment Cell Res. 2000;8:130-4.

26. Tsai CH, Tsai FJ, Wu JY, Lin SP, Chang JG, Yang CF, et al. Insertion/deletion mutations of type I oculocutaneous albinism in chinese patients from Taiwan. Hum Mutat. 1999:14:542.

27. Grønskov K, Ek J, Sand A, Scheller R, Bygum A, Brixen K, et al. Birth prevalence and mutation spectrum in danish patients with autosomal recessive albinism. Invest Ophthalmol Vis Sci. 2009;50:1058-64. https://doi. org/10.1167/iovs.08-2639.

28. Boissy RE, Nordlund JJ. Molecular basis of congenital hypopigmentary disorders in humans: a review. Pigment Cell Res. 1997;10:12-24.

29. Suzuki T, Miyamura Y, Matsunaga J, Shimizu H, Kawachi Y, Ohyama N, et al. Six novel $P$ gene mutations and oculocutaneous albinism type 2 frequency in Japanese albinopatients. J Invest Dermatol. 2003;120:781-3.

30. Chiang PW, Fulton AB, Spector E, Letter HFMR. Synergistic interaction of the OCA2 and OCA3 genes in a family. Am J Med Genet A. 2008;146A:2427-30. https://doi.org/10.1002/ajmg.a.32453.

31. Oetting WS, Garrett SS, Brott M, King RA. P gene mutations associated with oculocutaneous albinism type II (OCA2). Hum Mutat. 2005;25:323.

32. Rooryck C, Morice-Picard F, Elçioglu NH, Lacombe D, Taieb A, Arveiler B. Molecular diagnosis of oculocutaneous albinism: new mutations in the OCA14 genes and practical aspec. Pigment Cell Melanoma Res. 2008;21:583-7.

33. Duan HL, Li HY, Wu WQ, Zheng H, Chen Z. A novel P gene mutation in a Chinese family with oculocutaneous albinism. Zhonghua Yi Xue Yi Chuan Xue Za Zhi. 2006;23:614-7. 
34. Suzuki T, Miyamura Y, Tomita Y. High frequency of the Ala481Thr mutation of the $P$ gene in the Japanese population. Am J Med Genet A. 2003;118A:402-3.

35. Passmore LA, Kaesmann-Kellner B, Weber BH. Novel and recurrent mutations in the tyrosinase gene and the $\mathrm{P}$ gene in the German albino population. Hum Genet. 1999;105:200-10.

36. Spritz RA, Lee ST, Fukai K, Brondum-Nielsen K, Chitayat D, Lipson MH, Musarella MA, Rosenmann A, Weleber RG. Novel mutations of the P gene in type II oculocutaneous albinism (OCA2). Hum Mutat. 1997;10:175-7.

37. Spritz RA. Molecular genetics of oculocutaneous albinism. Hum Mol Genet. 1994;3:1469-75.

38. Yuasa I, Umetsu K, Harihara S, Miyoshi A, Saitou N, Park KS, et al. OCA2 481Thr, a hypofunctional allele in pigmentation, is characteristic of northeastern Asianpopulations. J Hum Genet. 2007;52:690-3.

\section{Publisher's Note}

Springer Nature remains neutral with regard to jurisdictional claims in published maps and institutional affiliations.

Ready to submit your research? Choose BMC and benefit from:

- fast, convenient online submission

- thorough peer review by experienced researchers in your field

- rapid publication on acceptance

- support for research data, including large and complex data types

- gold Open Access which fosters wider collaboration and increased citations

- maximum visibility for your research: over $100 \mathrm{M}$ website views per year

At BMC, research is always in progress.

Learn more biomedcentral.com/submissions 